\title{
The emergence of urban ozone episodes in autumn and air temperature rise in Hong Kong
}

\author{
Y. C. Lee • Mark Wenig • Xun Yang
}

Received: 31 July 2008 / Accepted: 12 March 2009 /Published online: 5 May 2009

(C) The Author(s) 2009. This article is published with open access at Springerlink.com

\begin{abstract}
In recent years urban photochemical episodes accompanied by unusually high ozone concentrations have been observed in the urban area of Hong Kong every autumn season except 2003. These episodes always occurred in summer time since 1990, but starting in 2000 additional autumn episodes could be observed. During those episodes the ozone concentrations exceeded the Hong Kong Air Quality Objective and reached an hourly maximum of $332 \mu \mathrm{g} \mathrm{m}^{-3}$ in September 2005. The maximum ozone concentrations of both summer and autumn episodes seem to be on an upward trend. It is the objective of this paper to examine a possible role of the air temperature factor in the emergence of ozone episodes in autumn. Significant correlations could be found between the maximum hourly ozone concentrations and the maximum and mean air temperatures during autumn months whereas the association between ozone and particulates is weaker. Autumn air temperature data from the Hong Kong Observatory headquarters and two ozone monitoring sites had been compared for the period from 1989 to 2007. This analysis takes into account the ozone trend and the unfavorable conditions posed by decreasing solar radiation and increasing cloud cover. Mean temperatures for October and November at the Hong Kong Observatory headquarters as well as two ozone monitoring
\end{abstract}

Y. C. Lee $(\bowtie) \cdot$ M. Wenig

Guy Carpenter Asia-Pacific Climate Impact Centre,

City University of Hong Kong,

Hong Kong, China

e-mail: yukclee@cityu.edu.hk

M. Wenig $\cdot$ X. Yang

Laboratory for Atmospheric Research, Department of Physics and

Materials Science, City University of Hong Kong,

Hong Kong, China sites (Sha Tin and Tai Po) show a slightly upward trend for the period under investigation. The September values, however, show a slight negative slope. The overall upward trend for air temperatures in autumn occurs at a time when the mean air temperatures in Hong Kong have been on the rise for over 120 years from 1885 to 2007, amidst the global warming trend. It is believed that the air temperature increase may have contributed to the emergence of urban ozone episodes in autumn in Hong Kong in 2000. Related to this influence of air temperature on ozone are high background pollutant concentrations in Hong Kong, as indicated by the minimum $\mathrm{PM}_{10}$ concentrations and the serious $\mathrm{NO}_{2}$ pollution dominating the Pearl River Delta region.

Keywords Autumn ozone episode · Hong Kong · Autumn air temperatures · Background pollution

\section{Background}

Photochemical pollution in Hong Kong

The Hong Kong Special Administrative Region (HKSAR) is situated on the coast of southern China (Fig. 1), at the mouth of the Pearl River estuary. It has an area of $1,100 \mathrm{~km}^{2}$ and a population of 6.96 million (as at end of 2007) (Census \& Statistic Department, HKSAR 2008). The climate is subtropical with hot and humid summers and cool and dry winters. Photochemical pollution is prevalent and is often associated with tropical storms which affect Hong Kong in summer and autumn. The main storm season is between July and October, when the equatorial convergence zone, where most storms develop, penetrates to about latitude $15^{\circ} \mathrm{N}$. 
Fig. 1 Hong Kong and southern part of the Pearl River Delta Region. $H K O$ indicates the Hong Kong Observatory headquarters

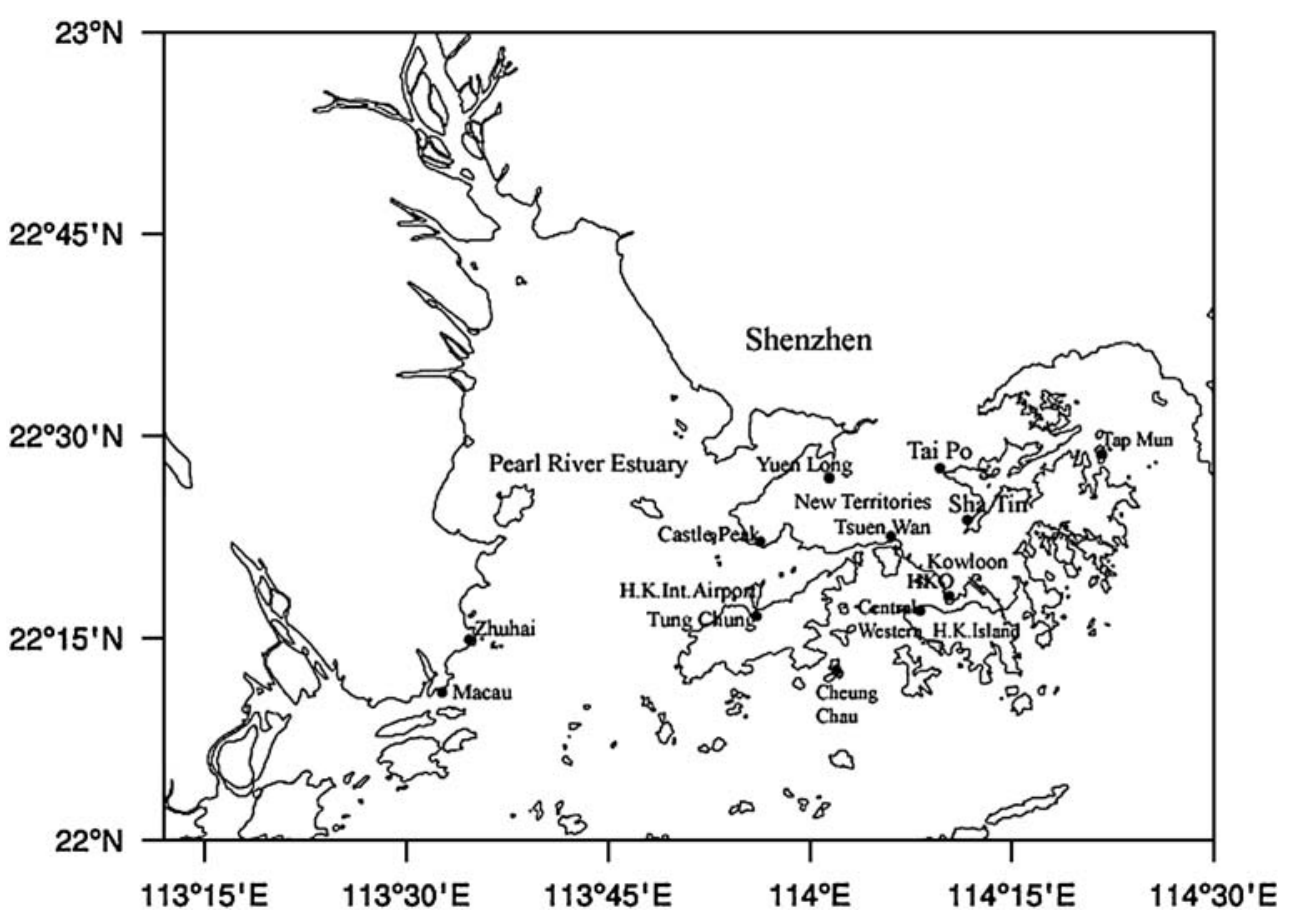

Altogether 25 summer ozone urban episodes occurred between 1994 and 2007. Nearly all were associated with tropical cyclones which induce northwesterlies (Lee et al. 2002) except for low pressure troughs on two occasions.

The significant number of 19 autumn urban episodes that occurred till 2007 were also, like the summer episodes, associated with tropical cyclones near Hong Kong. Autumnal ozone episodes were reported in cities like Kaohsiung in south-western Taiwan as well (Chen et al. 2003, Lin et al. 2007).

The impact of tropical storms on photochemical pollution in Hong Kong depends very much on their position relative to Hong Kong. In the past decade, a change in typhoon tracks was observed with typhoons being steered towards the vicinity of the East China Sea and Japan rather than into the South China Sea. It has been suggested that this more northerly track is due to a shift in the midtropospheric flow pattern, which in turn relates to increasing sea surface temperature in the South China Sea (Leung et al. 2007). However, it is not known whether this change in tracks has any effect on the occurrence of ozone episodes.

Most of the photochemical pollution in Hong Kong has been attributed to pollution in the Pearl River Delta (PRD) or more generally the south China Region, which is a major source of ozone precursors. Emissions in the PRD have been rising since the 1990s though they were once expected to be abated when the Flue Gas Desulphurization installation program was in place by 2007 . Hong Kong is directly downwind of the regional sources in the cooler monsoon seasons, whereas in summer, the precursors can still be brought in by northwest winds brought about by the tropical storms. Winds are generally southerlies in summer and bring in cleaner maritime air.

The once very serious suburban ozone episodes in Tung Chung occurred in summer, autumn, and spring, the worst season being summer, as in other parts of the world. The first urban ozone episode appeared in autumn at the beginning of this century. Since then, the severity of photochemical pollution in urban areas appears to have accelerated in summer as well as autumn and eventually urban concentrations exceed suburban maximum concentrations in 2007.

This paper focuses on the urban photochemical pollution of Hong Kong which emerges in the less likely autumn season. The main objective is to find out if this phenomenon is in any way related to the air temperature trend.

Air temperature and ozone formation

Meteorological conditions are known to influence ozone by affecting the photochemical environment, atmospheric circulation, and biogenic emissions of hydrocarbons (Lin et al. 2004). High solar radiation and air temperatures, low cloud cover giving clear sky conditions as well as a stable atmosphere are the main meteorological factors conducive to ozone formation in Hong Kong (Lee et al. 2002) as in other parts of the world. Among the meteorological factors, solar radiation and air temperature have been found to correlate strongly with ozone concentrations on a day-today basis (Lin et al. 2004; Tu et al. 2007). 
Urban ozone concentrations are enhanced by increases in ambient temperature which accelerate the conversion rates in the atmospheric chemistry. Higher temperatures also enhance biogenic hydrocarbon emissions and increase the abundance of $\mathrm{NO}_{x}\left(\mathrm{NO}+\mathrm{NO}_{2}\right)$ by thermal decomposition of the peroxyacetyl nitrate reservoir (Olszyna et al. 1997). Model calculations (Cardelino and Chameides 1990) also found ozone enhancement at higher temperatures.

Results of a modeling study for New York City (Civeroloa et al. 2007) suggest that extensive urban growth in the NYC metropolitan area has the potential to increase afternoon near-surface temperatures by more than $0.6^{\circ} \mathrm{C}$ and planetary boundary layer heights by more than $150 \mathrm{~m}$. Simulation results indicate that future changes in urbanization, with emissions held constant, may lead to increases in episode-average ozone levels by about 1-5 ppb and episode-maximum $8 \mathrm{~h} \mathrm{O}_{3}$ levels by more than $6 \mathrm{ppb}$ across much of the NYC area.

\section{Air temperature rise in Hong Kong}

According to the Hong Kong Observatory, mean air temperatures in Hong Kong have been on the rise for over 120 years from 1885 to 2007 (Hong Kong Observatory 2008). The mean temperature and mean minimum temperature are found to increase at the surface at the Hong Kong Observatory headquarters (situated in the Kowloon peninsula of Hong Kong; Fig. 1) (Lam 2006; Leung et al. 2004) and in the lower troposphere, but decrease in the upper troposphere and lower stratosphere. The annual mean temperature recorded in the post-war years 1947 to 2007 (Fig. 2) was found to rise at $0.17^{\circ} \mathrm{C}$ per decade, in line with the global warming trend. Between 1989 and 2007, the rate increased sharply to $0.34^{\circ} \mathrm{C}$ per decade. The faster rate of warming in Hong Kong than the global trend since the early 1980s has been attributed to rapid urbanization (Lam 2006) which intensifies urban heat islands (Cardelino and Chameides 1990).

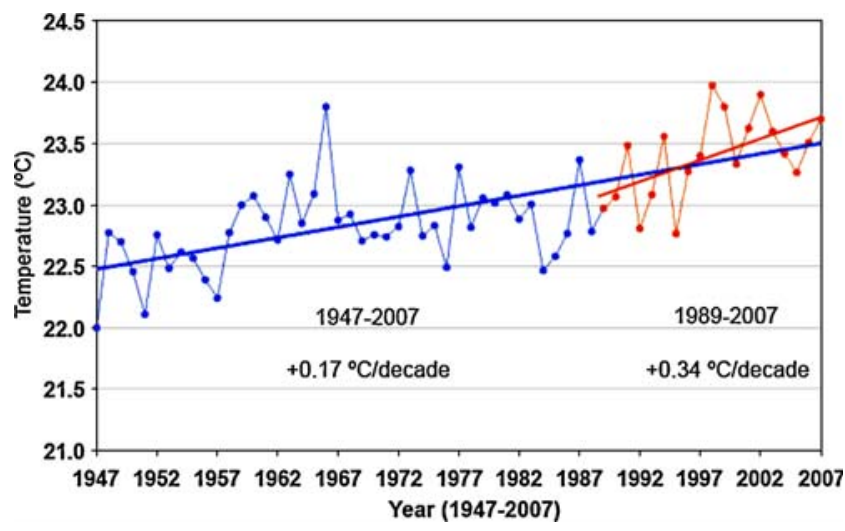

Fig. 2 Annual mean temperature recorded at the Hong Kong Observatory headquarters, 1947-2007 (www.hko.gov.hk)
Urban heat island intensity (Giridharan et al. 2004; Leung et al. 2004) values are found to be proportional to the extent of urbanization.

Despite the rising trends of the mean temperatures and mean minimum temperature in Hong Kong, the trend of daily maximum temperature was found to decrease (Leung et al. 2004). The Hong Kong Observatory has suggested that the general decrease in maximum temperature is related to the decreasing trend in the observed global solar radiation reaching the surface. This, in turn, has been linked to an increase in the concentration of condensation nuclei in the air, a result of increased urbanization and increased cloud amount in Hong Kong. Leung et al. (2004) have suggested that while the increase in particulates in the atmosphere reduces the amount of solar radiation reaching the ground, this may, however, be offset by the heat generated by urban activities.

A similar warming trend is reported in mainland China. A recent report by the Guangdong Meteorological Bureau (GMB 2007 at www.grmc.gov.cn) indicates that the temperature in the PRD region has risen by an average of $0.21^{\circ} \mathrm{C}$ per decade over the past 50 years. Compared with regions south of the Yangtze River, the warming trends are found to be much larger in mid to high latitudes of western, eastern, and northern China. The most significant temperature increase occurred in winter (National Development and Reform Commission, PRC 2007).

\section{Other meteorological factors}

Similar to some parts of the world (Stanhill and Cohen 2001; Roderick 2005) such as the USA (Liepert 2002), the annual mean daily global solar radiation in Hong Kong (measured at King's Park, Hong Kong) has decreased significantly at a linear rate of $0.84 \mathrm{MJm}^{-2}$ per decade for the whole period of 1964 and 2007 (Hong Kong Observatory 2008). On the other hand, the annual mean cloud amount was reported (Hong Kong Observatory 2008) to be increasing at a rate of $1.3 \%$ per decade in the period of 1961 to 2007.

\section{Background precursors and ozone formation}

It has been suggested by Simmonds et al. (2004) that enhanced emissions of anthropogenic photochemical precursors have caused global background ozone to increase during the past century. Vingarzan (2004) found that background ozone levels over the mid-latitudes of the Northern Hemisphere have continued to rise over the past three decades, in the range of approximately $0.5-2 \%$ per year while model sensitivity studies indicate that the rise in $\mathrm{NO}_{x}$ emissions accounts for the greatest increase in background ozone levels. 
A notable phenomenon is the transport of Asian pollutants, particularly that of China, to western North America and forms a substantial component of the background ozone concentration in that part of the continent (NOAA 2003). Boersma et al. (2007) have estimated that the tropospheric ozone concentrations in the entire northern hemisphere have increased due to the growing emissions in China. In OMI images from NASA (Bucsela et al. 2006), the $\mathrm{NO}_{2}$-plagued industrial regions in China, including the Pearl River Delta region, are clearly visible. Hong Kong is located right at the southeastern end of the Pearl River Delta Region.

\section{Source of data and statistical tests for normality of data}

The ozone concentration data for the monitoring sites Sha Tin and Tai Po used in this paper for analysis have been obtained from the Environmental Protection Department (EPD) of the Hong Kong SAR which is also available at http://epic.epd.gov.hk/ca/uid/airdata/p/1. The monitoring network of the EPD comprises 14 fixed multi-parameter monitoring stations (three being roadside stations) each installed with a combination of continuous gaseous $\left(\mathrm{SO}_{2}\right.$, $\mathrm{NO}_{2}, \mathrm{CO}$, and $\mathrm{O}_{3}$ ) analyzers and particulate monitors. The Sha Tin station is located in the Sha Tin Government Secondary School, in a residential district in Tai Wai while the Tai Po station is at the rooftop of the Tai Po Government Office Building, which is also in a residential district. The sampling heights for the Sha Tin and Tai Po stations are $27 \mathrm{~m}$ and $31 \mathrm{~m}$, respectively. The Sha Tin station began operation in 1991 and Tai Po in 1990.

Ozone is measured by the API 400, API 400A (EPD 2007) instruments based on UV absorption. Data quality control procedures include periodic calibrations and data validation and assessment procedures with performance and system audits. The stations have been accredited by the Hong Kong Accreditation Service since 1996.

Aerosol size distribution is obtained by using a PREDE POM-01 sun-sky radiometer installed in the main campus of the City University of Hong Kong in Kowloon. By measuring the direct and scattered solar radiation and applying the inversion algorithm, columnar aerosol optical properties like size distribution can be obtained.

Meteorological data are obtained from the Hong Kong Observatory (HKO). Surface observations of air temperature (dry-bulb temperature) are known to be taken at the Hong Kong Observatory by platinum resistance thermometers. The air temperature data for Sha Tin and Tai Po are obtained from HKO's territorywide network of automatic weather station for measuring wind, pressure, temperature, humidity, and rainfall.
Global solar radiation is measured by a thermo-electric pyranometer at King's Park (in Kowloon) while visual observations of cloud amount were made hourly at the Hong Kong Observatory. The meteorological data from the Hong Kong Observatory has also gone through established quality control and assurance procedures.

The ozone concentration, air temperature (maximum and moving averages of daily means), annual mean daily global solar radiation, and annual mean cloud amount data have been checked by the Kolmogorov-Smirnoff test for similarity to the normal distribution. The $P$ values obtained, listed as asymptotic significance (twotailed) are at a value of 0.05 or better, except for part of the long-term air temperature data. Most of the data therefore do not differ from a normal distribution at the 0.05 level.

To reduce short-term variations including meteorological changes as far as possible, moving averages of daily air temperatures (at an interval of 30 days) are computed for the analysis of long-term trends in section Air temperature factors. This interval is found to provide satisfactory $R^{2}$ values.

\section{Ozone concentrations versus air temperatures in Hong Kong}

To better define the relationship between ozone concentrations and air temperatures in Hong Kong, a least squares regression analysis is performed on the data. Maximum hourly ozone concentrations at two local monitoring sites (Sha Tin and Tai Po, see Fig. 1 for locations) are plotted against daily maximum and mean temperatures recorded at the same sites by the Hong Kong Observatory for the autumn months of 1997-2007 (Fig. 3).

The regression lines obtained indicate a close association between ozone and the air temperature parameters, with significant positive correlation coefficients of 0.6 and 0.5 , respectively for daily maximum and mean temperatures. As expected, the daily maximum temperatures have a higher correlation with ozone.

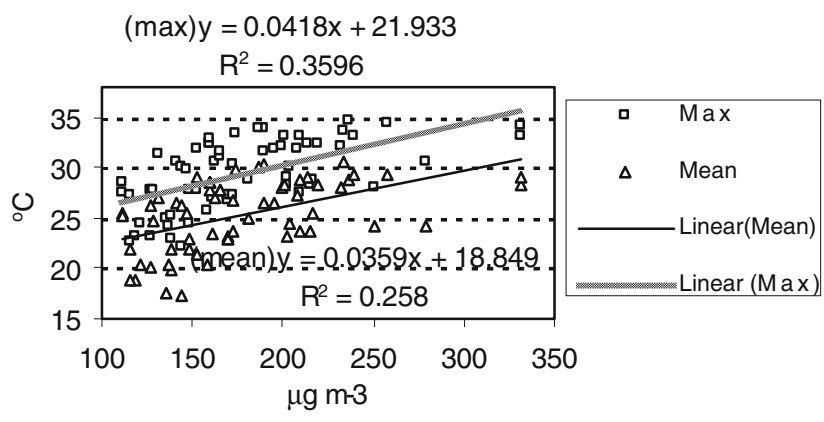

Fig. 3 Maximum ozone concentrations in autumn versus maximum and mean air temperatures, Hong Kong (Sha Tin, Tai Po) 1997-2007 


\section{Trends of episodic ozone concentrations in Hong Kong}

As evident from Fig. 4, ozone concentrations in Hong Kong have been on a generally upward trend since the early 1990s. Notably, suburban ozone maxima have been, until 2006, higher than urban concentrations, reaching the highest level in 2004 in the suburban town of Tung Chung (see Fig. 1 for location) on the western part of Hong Kong, at the mouth of the Pearl River estuary. The apparent reasons for this extremely high photochemical pollution in 2004 are mainly the increase in emissions from a local power plant and to some degree, contribution of regional air pollution as Hong Kong is downwind of almost all pollution sources in the Pearl River Delta under episodic conditions.

\section{Summer episodic ozone concentrations}

Summer ozone episodes have been reported for both urban and suburban areas of Hong Kong (Lee et al. 2002; Lee and Savtchenko 2006). Figure 5 shows the maximum summer ozone concentrations in the urban areas during the period of 1994-2007, revealing a mild upward trend. The all-time high hourly concentrations of 328 and $327 \mathrm{\mu g} \mathrm{m}^{-3}$ (at Yuen Long and Central Western stations) (see Fig. 1 for locations) were measured in August of 2006 and 2007, respectively. However, they are lower than the maximum suburban summer concentrations of $370 \mu \mathrm{g} \mathrm{m}^{-3}$ reported at the rural site of Tap Mun (see Fig. 1 for location) on eastern Hong Kong in August 2006.

Ozone episode emerges in autumn in urban areas in 2000

In Hong Kong, photochemical episodes had occurred only in summer until 2000, when an exceedance of $240 \mu \mathrm{g} \mathrm{m}^{-3}$, which is the 1-h Hong Kong Air Quality Objective for ozone, was recorded at the Central Western monitoring station on the Hong Kong Island in autumn. This station then records the most autumn episodes (a total of five) in

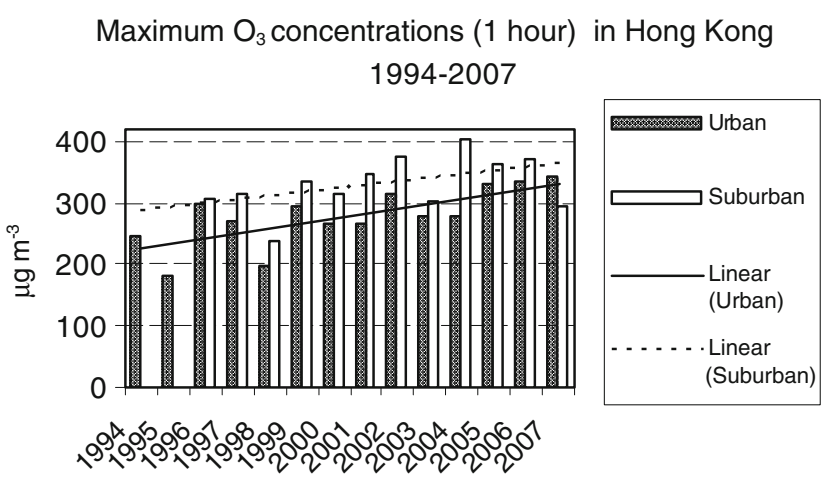

Fig. 4 Maximum ozone concentrations (1 h) in Hong Kong 1994-2007
Maximum $\mathrm{O}_{3}$ concentration during urban autumn \& summer episodes 1994-2007

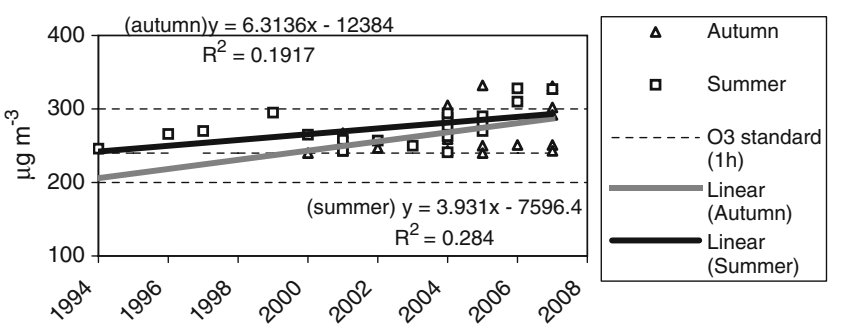

Fig. 5 Maximum ozone concentrations during urban autumn and summer episodes in Hong Kong 1994-2007 (urban autumn episodes first appeared in 2000)

subsequent years. Figure 5 shows the maximum $1 \mathrm{~h}$ ozone concentrations measured in autumn since 2000 .

It becomes apparent that the urban ozone concentrations have been trending up. The maximum episodic concentration was $332 \mu \mathrm{g} \mathrm{m}^{-3}$ recorded in September of 2005. The most recent exceedance of $331 \mu^{-3} \mathrm{~m} \mathrm{~m}^{-3}$ was recorded on 6 October 2007 at Sha Tin, which is a hotspot for ozone episodes, whether summer or autumn.

\section{Air temperature factors}

Status of main meteorological factors

Air temperature, solar radiation, and cloud cover directly affect ozone production. Regarding the cloud cover, it is known to be increased or decreased by aerosols in different places and times (NASA 2008). It is believed that in Hong Kong, the large number of aerosols suspended in the air during pollution episodes or events make less water available for condensation on each particle. This will result in a larger number of small droplets in each cloud which last longer and create more cloud cover. The larger number of droplets will reflect more of the sun's heat and energy into space. The decreasing trend of the cloud cover and the changes in solar radiation in Hong Kong are shown in Fig. 6 for the urban ozone episode days occurring in autumn from 2000 to 2007 .

Air temperature trend in autumn

\section{At the Hong Kong Observatory headquarters}

Both the mean temperature and the mean minimum temperature of Hong Kong in the period of 1947-2002 (Leung et al. 2004) were rising for all the seasons. However, the rate of increase of mean temperatures was found to be greatest in winter $\left(0.21^{\circ} \mathrm{C}\right.$ per decade $)$ and smallest in autumn $\left(0.12^{\circ} \mathrm{C}\right.$ per decade). 
Daily global solar radiation( $\left.\mathrm{MJ} \mathrm{m}^{-2}\right)$ \& mean amount of cloud (\%) on urban autumn episode days 2000-2007

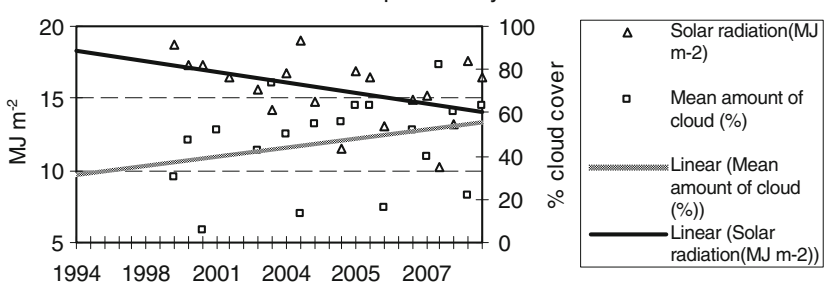

Fig. 6 Daily global solar radiation $\left(\mathrm{MJ} \mathrm{m}^{-2}\right.$ ) and mean amount of cloud (\%) on urban autumn episode days 2000-2007

As for the autumn months, which are the focus of this paper, 30-day moving averages of the mean temperatures recorded at the Hong Kong Observatory headquarters for each of the months of September, October, and November are plotted for a more recent period of 1990 to 2007 . A sharp increase of $0.34^{\circ}$ $\mathrm{C}$ per decade was previously reported for the entire autumn for this period (section Air temperature rise in Hong Kong of this paper). As shown in Fig. 7, the mean temperatures of both October and November show a slight upward trend. However, a slight negative slope is found for September.

\section{At the ozone monitoring sites}

Sha Tin and Tai Po (Fig. 1) in the New Territories are the only monitoring sites in Hong Kong where both meteorological (from the Hong Kong Observatory) and ozone data (from the Environmental Protection Department, since 1997) are available for parallel comparisons.

Summer photochemical pollution could be observed frequently in Sha Tin since starting the ozone record in June 1997. The monitoring results from 1994 to 2007 reveal that as many as 12 of the 17 territory-wide ozone episodes recorded in the summer season in the urban areas of Hong Kong have their maxima reported in Sha Tin.

Sha Tin first reported autumn ozone exceedance in 2005, and recorded four episodes since then. As shown earlier in section Trends of episodic ozone concentrations in Hong Kong, the ozone concentrations on both the summer and autumn episode days appear to be on the rise, with those of autumn rising more steeply.

Consistent with the measurements at the Hong Kong Observatory headquarters, 30-day moving averages from 1989/1990 to 2007 for Sha Tin and Tai Po (Fig. 8) showed a similar upward trend for the mean temperatures of October and November but again not for September. Trendline equations are given in the respective plots for the mean temperatures of the autumn months. In view of the close association of ozone concentrations with air temperatures, amid the highly significant decrease in solar radiation and the increase in mean amount of cloud, it appears likely that the general upward trend of air
Fig. 7 Mean air temperatures in September, October, and November at the Hong Kong Observatory Headquarters, Hong Kong, 1990-2007

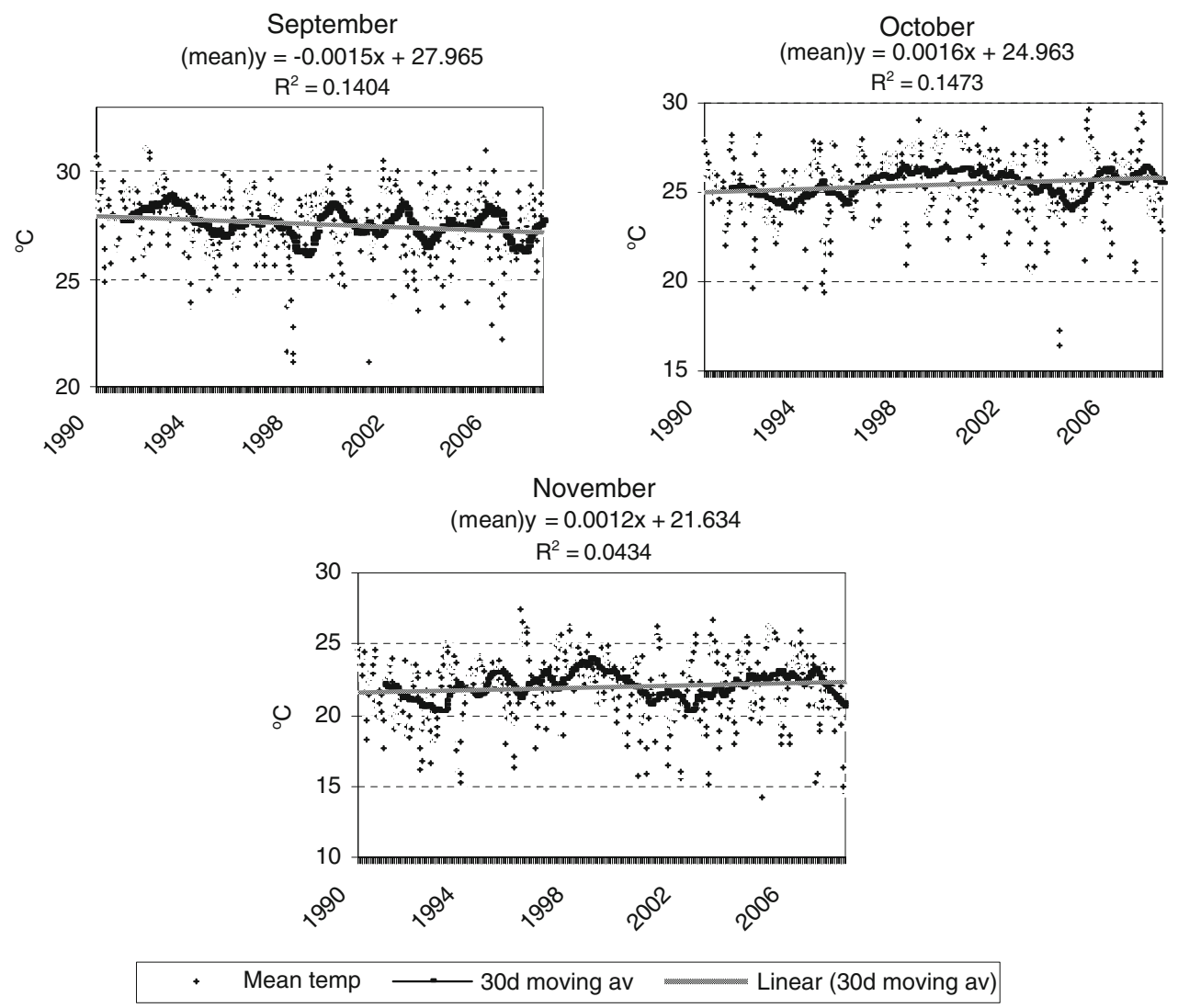


Fig. 8 Maximum and mean air temperature in the autumn months at urban ozone monitoring sites in Hong Kong (Sha Tin, Tai Po) 1989/1990-2007
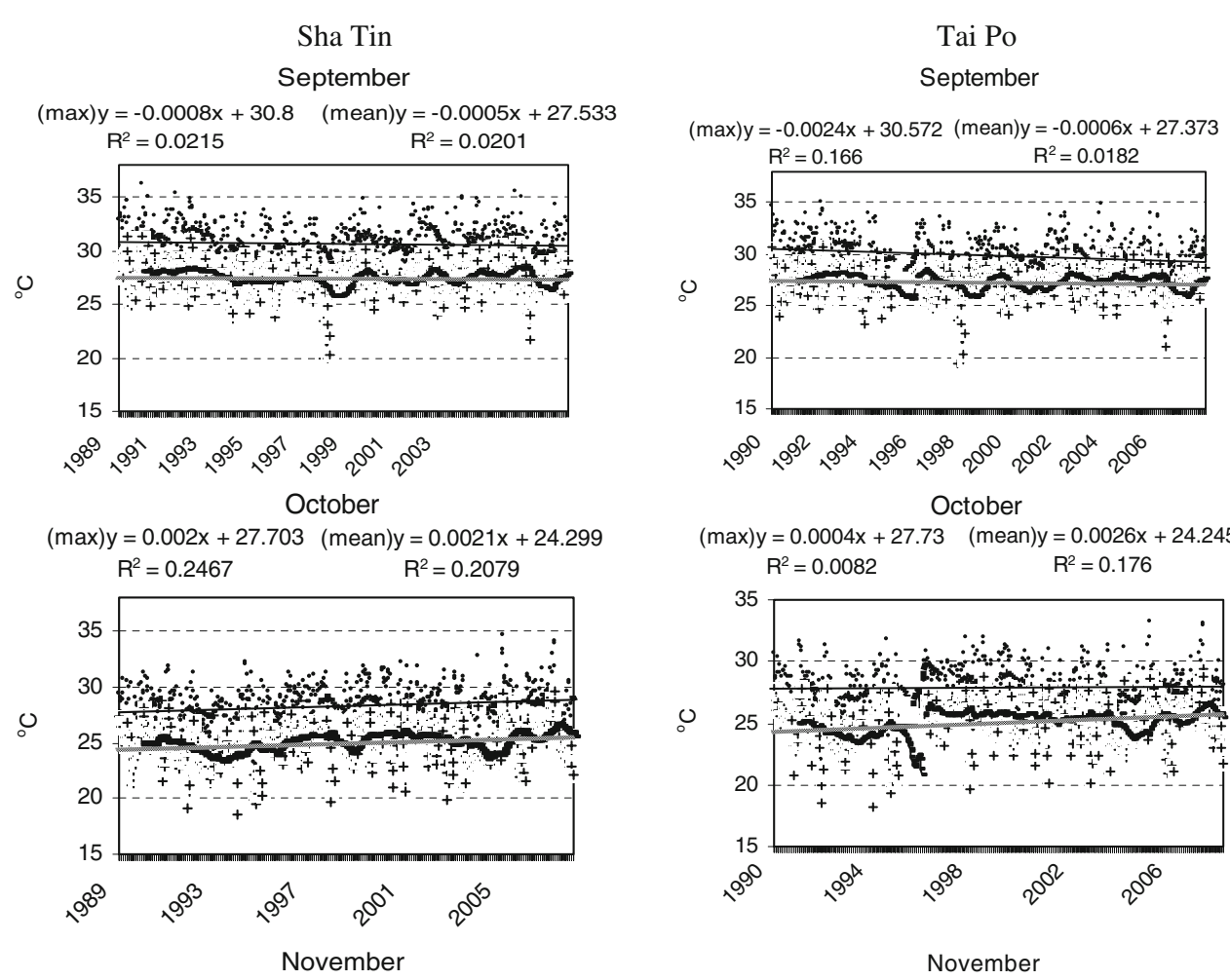

$(\max ) y=0.0004 x+27.73 \quad($ mean $) y=0.0026 x+24.245$

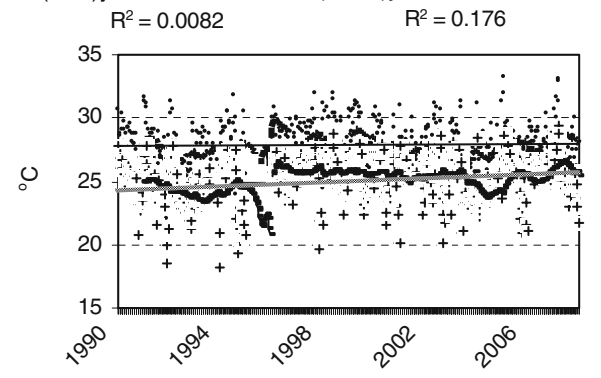

November

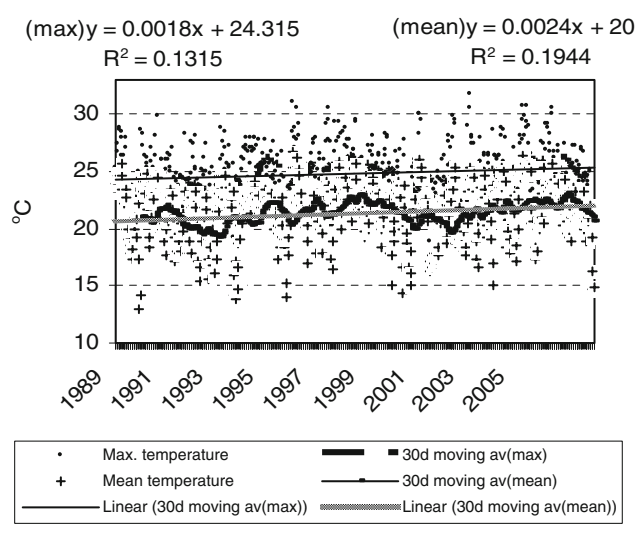

$(\max ) y=3 E-05 x+24.38 \quad($ mean $) y=0.002 x+20.787$

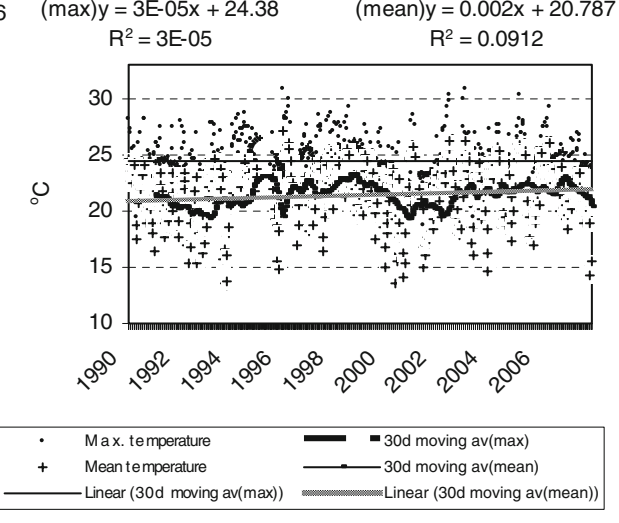

temperatures has contributed to the apparently rising ozone levels in urban areas and the emergence of urban ozone episodes in the autumn season in Hong Kong. This is despite the fact that meteorological variations and year to year changes may cause differences.

As for the maximum daily temperatures (as 30-day moving averages), an increasing trend is found only for October and November in Sha Tin and October in Tai Po. As suggested earlier in section Air temperature rise in Hong Kong, the slight decreasing trends in maximum daily temperatures found in other stations (e.g. Tai Po) for the same period may be related to an increase in atmospheric particulates which leads to reduction in solar radiation. Regarding the locations of the monitoring sites, it should be noted that the blocking of airflow in the valley of Sha Tin may favor air temperature rise as compared to other urban areas of Hong Kong.
Urbanization and air temperature rise

The concentration of heat in urban heat islands arises from a combination of factors in Hong Kong as in other cities, including replacement of vegetation by heat-absorbing concrete and asphalt surfaces, reduced air mixing, motor vehicle emissions and other anthropogenic heat sources. The daily pattern of heat flow changes as a result and forms heat islands. The abundant concrete surfaces in the rapidly urbanized city area and satellite towns of Hong Kong simply retain the heat during the day and release it as long-wave radiation during the night. This will result in a slower fall of temperatures at night and a higher minimum temperature.

Urban heat island intensity is defined in Hong Kong by the difference between the air temperature measured at a specific location and the air temperature at the Cheung Chau Island Station (see Fig. 1 for location) in the southern part of Hong 
Kong (Hong Kong Observatory). Out of nine urban areas in Hong Kong, Tai Po and Sha Tin rank fourth and sixth respectively (in descending order) for urban heat island intensity for mean air temperature on the recent autumn episode day of 6 October 2007. This suggests that these ozone monitoring sites are not as highly urbanized as other areas in the territory and urbanization does not play as significant a role in air temperature rise as elsewhere.

\section{Background precursor concentrations}

$\mathrm{NO}_{2}$ and volatile organic compounds are the known main precursors for ozone formation. The formation of secondary particulate matter is often attributable to the same precursors. $\mathrm{PM}_{10}$, which is much less reactive and has less diurnal variations than other pollutant species, is a convenient means to track background pollution.

The secondary aerosol part of $\mathrm{PM}_{10}$ is generated by photochemical oxidation processes and is mainly in the fine size range. The average aerosol size distribution in July and October from 2002 to 2004 is shown in Fig. 9. A bimodal size distribution is observed. The fine mode has a radius ranging from 0.01 to $0.6 \mu \mathrm{m}$ while the coarse mode is located from 0.6 to $16 \mu \mathrm{m}$. While anthropogenic aerosols contribute mainly to the fine mode, the coarse mode comprises significant amounts of sea salt aerosols. The columnar aerosol concentrations obtained by integrating the size distribution, is obviously higher in October. $\left(1.13 \mu \mathrm{m}^{3} \mu \mathrm{m}^{-2}\right)$ than in July $\left(1.17 \mu \mathrm{m}^{3} \mu \mathrm{m}^{-2}\right)$. October also has a higher concentration fraction $(48 \%)$ of fine aerosol than July (42\%).

A regression of maximum ozone concentrations against maximum and mean $\mathrm{PM}_{10}$ (Fig. 10) yields correlation

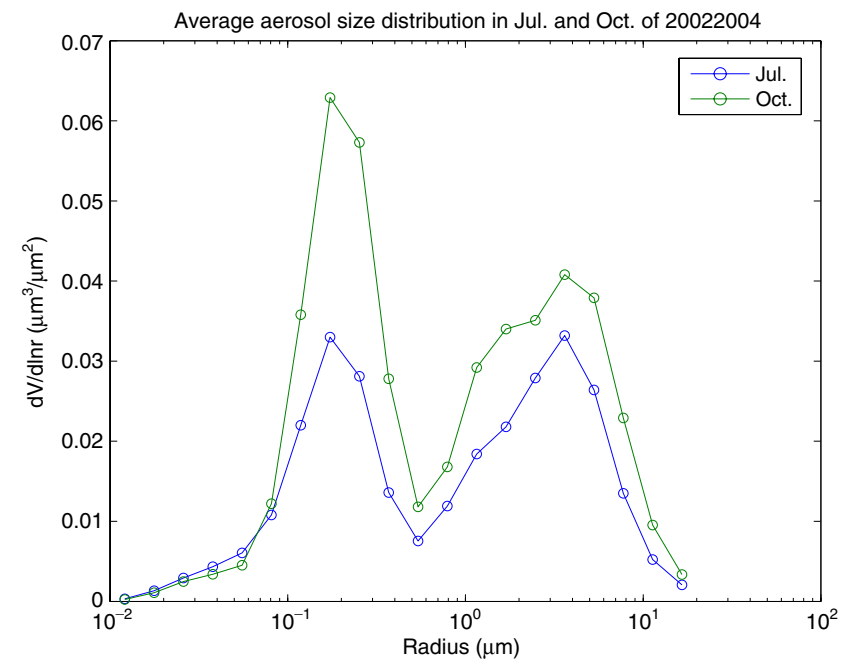

Fig. 9 Average aerosol size distribution for October and July in Hong Kong 2002-2004
Maximum $\mathrm{O}_{3}$ concentration in autumn vs maximum \& mean $\mathrm{PM}_{10}$ (at the same site) on autumn episode days

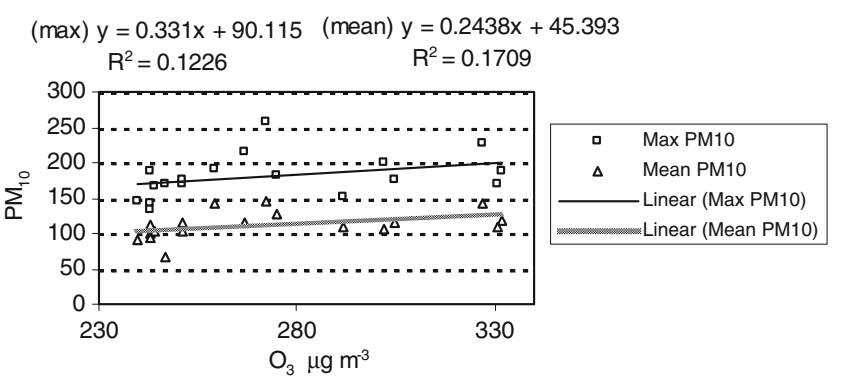

Fig. 10 Maximum $\mathrm{O}_{3}$ concentration in autumn vs maximum and mean $\mathrm{PM}_{10}$ (at the same site) on autumn episode days

coefficients of 0.35 and 0.41 , respectively, suggesting a slightly weaker relationship between ozone and precursor concentrations, than between ozone and air temperatures.

Minimum $\mathrm{PM}_{10}$ concentration in Sha Tin for October, now a favorable month for ozone episodes, ranges from $4 \mu \mathrm{g}$ $\mathrm{m}^{-3}$ in 1993 to $29 \mu \mathrm{g} \mathrm{m}^{-3}$ in 2004 for the period of 1994 to 2007 (Fig. 11) while that of Tai Po has decreased from $31 \mu \mathrm{g}$ $\mathrm{m}^{-3}$ in 1997 to $7 \mathrm{\mu g} \mathrm{m}^{-3}$ in 2002/2007, showing a slight negative trend. An upward trend is observed in Sha Tin, with maximum concentrations recorded in the years 2004 and 2007, when pollution from local power stations was believed to be at a serious level. The greater number of urban ozone episodes occurring in 2004 and 2007 is no coincidence. The Castle Peak Power Station with a capacity of 4,108 MW has reported that their $2007 \mathrm{NO}_{2}$ and particulate emissions had, compared with 2006 , increased by $25 \%$ and $5 \%$, respectively. A similar upward trend is found in the $\mathrm{PM}_{10}$ annual averages (Fig. 11).

However, it is clear that Hong Kong's background pollutant concentrations are not solely caused by local stationary and mobile sources, but very significantly by pollution in the Pearl River Delta/south China region, especially in the downwind seasons. Back trajectories of up to $36 \mathrm{~h}$ in time to Hong Kong are generated for specified starting heights and times by the Windows-based Hybrid Single-Particle Lagrangian Integrated Trajectory Model of Air Resources Laboratory of the US

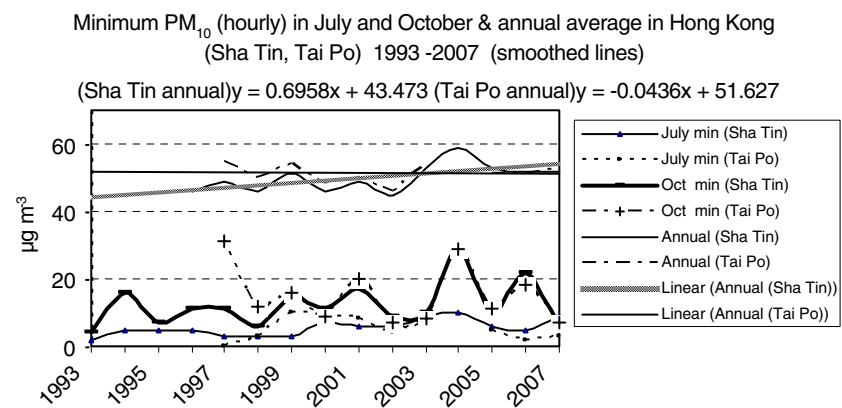

Fig. 11 Minimum $\mathrm{PM}_{10}$ (hourly) in July and October and annual average in Hong Kong (Sha Tin, Tai Po) 1993-2007 
Fig. 12 Back trajectories of air masses arriving at Hong Kong on autumn episode days of a 11 September 2005 and b 6 October 2007
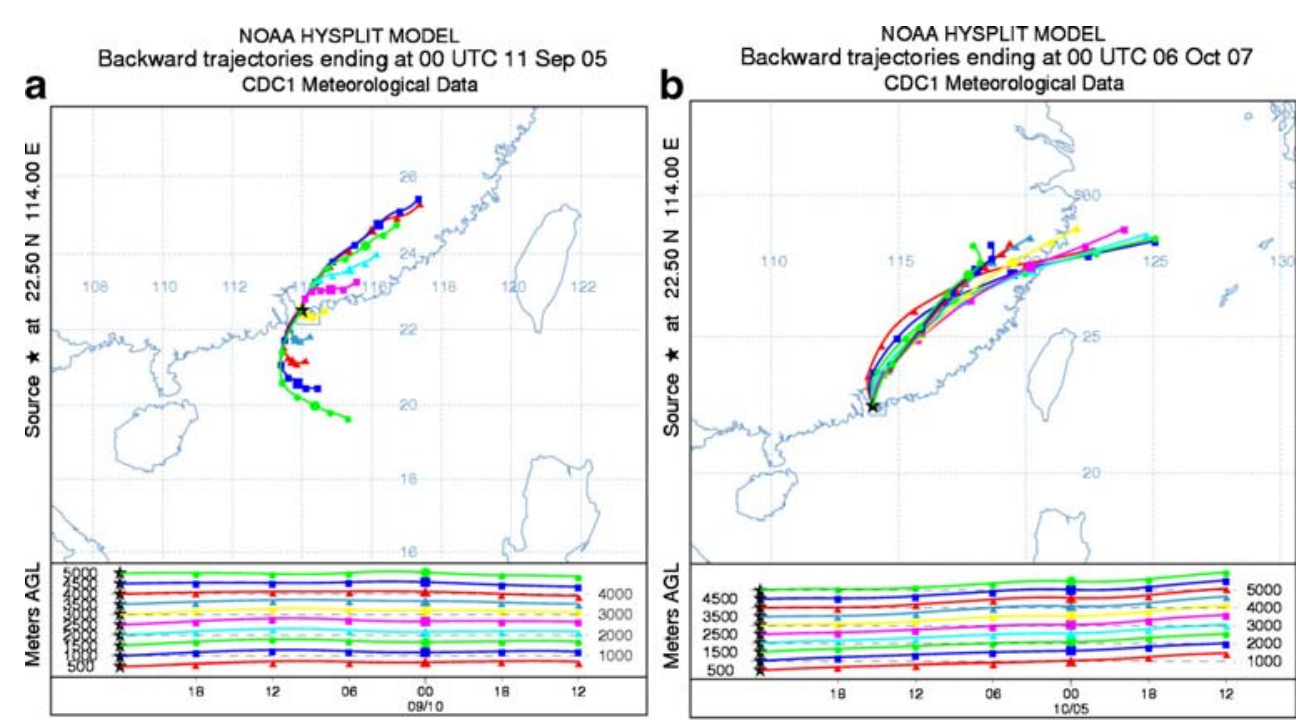

National Oceanic and Atmospheric Administration (NOAA) (http://www.ready.noaa.gov/ready/hysp_info. html). Trajectories for two more recent territory-wide episode days of 11 September 2005 and 6 October 2007 are presented in Fig. 12, showing the passage of air parcels before arriving at Hong Kong at 00 Universal Coordinated Time at ten altitudes from $500 \mathrm{~m}$ to $5,000 \mathrm{~m}$, at 500-m intervals. Results indicate pollutant transport into Hong Kong from upwind sources in the Pearl River Delta/south China region except for the inflow of marine air masses at higher altitudes $(3,000$ $5,000 \mathrm{~m}$ ) on 11 September 2005.

The regional influence on Hong Kong is also illustrated in Fig. 13 which shows high tropospheric $\mathrm{NO}_{2}$ in the Pearl River Delta Region on the two episode days. The maximum ozone concentrations were measured in Sha Tin, one of the two ozone monitoring sites studied.

In comparison to the serious regional influence on Hong Kong, especially in the downwind seasons, the increase in global background ozone and other pollutants clearly has a relatively insignificant influence on the territory.

Apparently, the air quality of the Pearl River Delta has not improved despite the desulphurization efforts in the Pearl River Delta/south China Region in this century, contrary to expectations. In fact it was reported that the situation had worsened with record hazy days registered in 2007 — with an average of 75.7 days of haze which is "the most since 1949" (People's Daily 2008). Most of the cities and counties in the region saw more than 100 hazy days in the year. It has even been estimated that it may take 20 or 30 years to bring the haze under control.

\section{Conclusions}

Photochemical pollution is prevalent in Hong Kong and is often associated with tropical storms which affect Hong
Kong in both summer and autumn. The suburban photochemical problem has become increasingly serious, especially in summer. In the past urban ozone episodes only appeared in summer since 1990 when measurements were first made, but starting in September 2000 episodes in autumn could be recorded as well. It was first measured at a monitoring station (Central Western) in the urban area of Hong Kong Island, with a mild exceedance of the Hong Kong Air Quality Objective for ozone. Since then, ozone episodes have occurred in every autumn season except 2003. The maximum ozone concentrations of both summer and autumn episodes in urban areas appear to be on an upward trend during the period of 1994 to 2007. This is despite a significant decrease in global solar radiation and an increase in average cloud cover recorded by the Hong Kong Observatory as illustrated in this paper.

To better define the relationship between ozone concentrations and air temperatures in Hong Kong, least squares regression analysis was performed on the maximum hourly ozone concentrations at two local monitoring sites (Sha Tin and Tai Po) and daily maximum and mean temperatures (measured by the Hong Kong Observatory) at the same sites for the autumn months of 1997-2007, the period for which ozone data are available. One of the sites, Sha Tin, has been a photochemical pollution hotspot since monitoring commenced in this site in June 1997. It is clear from the regression analysis that the maximum hourly ozone concentrations have significant positive correlations with maximum and mean temperatures $(r=0.6$ and 0.5 , respectively) for the autumn months.

$\mathrm{PM}_{10}$, which is much less reactive and has less diurnal variations than other pollutant species, is used as an indicator of background precursor concentrations. A regression of maximum ozone concentrations against maximum and mean $\mathrm{PM}_{10}$ yields correlation coefficients of 0.35 and 0.41 , respectively, suggesting a slightly weaker 
Fig. 13 Tropospheric $\mathrm{NO}_{2}$ in southeast Asia on the territorywide episode days of a 11 September 2005 and b 6 October 2007
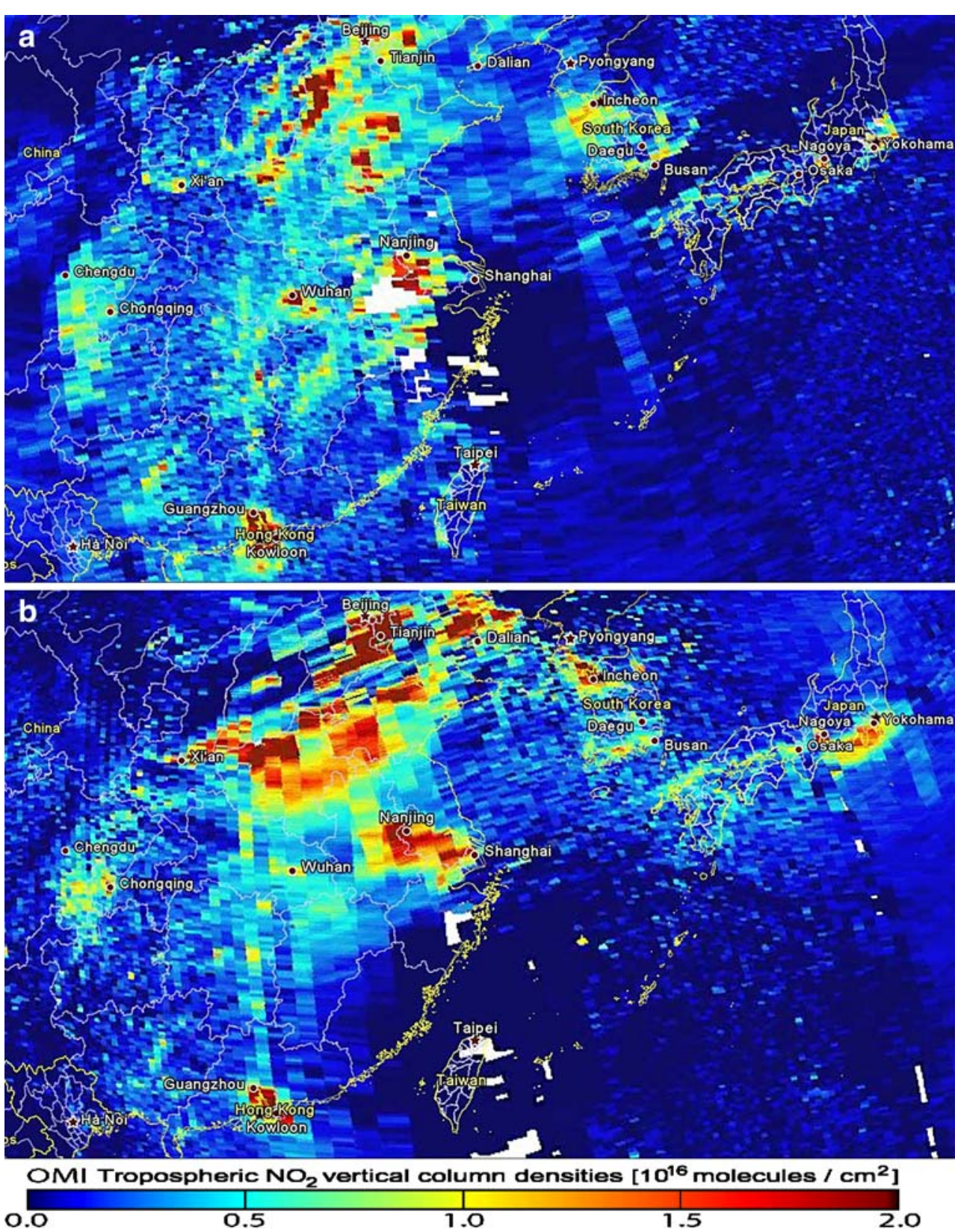

relationship between ozone and precursor concentrations, than between ozone and air temperature. The background pollutant concentrations are on an upward trend in one of the monitoring sites, as indicated by the minimum $\mathrm{PM}_{10}$ concentration (Sha Tin) in July and October over the years 1994 to 2007.

In view of the close association between maximum hourly ozone concentrations and the daily maximum and mean temperatures, air temperature data from the Hong Kong Observatory headquarters and two ozone monitoring sites are analyzed for the individual autumn months.

Results indicate that mean temperatures of October and November at the Hong Kong Observatory headquarters are on a slightly positive trend for the period of
1990 to 2007 while the September means slightly decrease. Consistent with the measurements at the Hong Kong Observatory, data from 1989/1990 to 2007 for two ozone monitoring sites in Hong Kong (Sha Tin and Tai Po) show a similar slight upward trend for the mean temperatures of October and November but a slightly negative slope for September. As for the maximum daily temperatures, an increasing trend is found in October and November in Sha Tin and October in Tai Po. However, the valley topography of Sha Tin is believed to favor air temperature rise.

The upward trends for the autumn months occur at a time when the solar radiation and cloud cover do not favor ozone formation. Indeed, the mean air temper- 
atures in Hong Kong have been on the rise for over 120 years from 1885 to 2007, amidst the global warming trend. The annual mean temperature was found by the Hong Kong Observatory to rise at $0.17^{\circ} \mathrm{C}$ per decade in the post-war years 1947 and 2006. Though seasonally, the rate of increase of mean temperatures was found by the HKO to be greatest in winter and smallest in autumn, it appears likely that the air temperature increases have contributed to the emergence of urban ozone episodes in the autumn season in Hong Kong, besides the role of ozone precursor concentrations in the Pearl River Delta region. Clearly, it still remains to be seen whether the 1997 to 2007 ozone concentration and air temperature measurements will continue in the existing trend.

Acknowledgements The work described in this paper was substantially supported by a grant from City University of Hong Kong (Project No. 7002322) and thanks are due to the Guy Carpenter Asia-Pacific Climate Impact Centre of the City University of Hong Kong for research grant support as well as the Environmental Protection Department and the Hong Kong Observatory of the Hong Kong Special Administrative Region for the provision of air quality and meteorological data.

Open Access This article is distributed under the terms of the Creative Commons Attribution Noncommercial License which permits any noncommercial use, distribution, and reproduction in any medium, provided the original author(s) and source are credited.

\section{References}

Boersma KF, Eskes HJ, Veefkind JP, Brinksma EJ, Van Der ARJ, Sneep $\mathrm{M}$, van den Oord GHJ, Levelt PF, Stammes P, Gleason JF, Bucsela EJ (2007) Near-real time retrieval of tropospheric $\mathrm{NO}_{2}$ from OMI. Atm Chem Phys 6:12301-12345 sref:1680-7324/acp/2007-7-2103

Bucsela EJ, Celarier EA, Gleason JF, Wenig MO, Veefkind JP, Boersma KF, Brinksma E (2006) Algorithm for $\mathrm{NO}_{2}$ vertical column retrieval from the Ozone Monitoring Instrument. IEEE Trans Geosci Rem Sens 44(5):1245-1258. doi:10.1109/ TGRS.2005.863715

Cardelino CA, Chameides WL (1990) Natural hydrocarbons, urbanization, and urban ozone. J Geophys Res 95:13971-13979

Census \& Statistic Department (2008), Hong Kong Special Administrative Region (http://www.censtatd.gov.hk/hong_kong_statistics/ index.jsp)

Chen KS, Ho YT, Lai CH, Chou Y-M (2003) Photochemical modeling and analysis of meteorological parameters during ozone episodes in Kaohsiung, Taiwan. Atmos Environ 37(13):1811-1823. doi:10.1016/S1352-2310(03)00079-7

Civeroloa K, Hogrefe C, Lynn B, Rosenthal J, Ku J-Y, Solecki W, Cox J, Small C, Rosenzweig C, Goldberg R, Knowlton K, Kinney P (2007) Estimating the effects of increased urbanization on surface meteorology and ozone concentrations in the New York City metropolitan region. Atmos Environ 41(9):1803-1818. doi:10.1016/j.atmosenv.2006.10.076

Environmental Protection Department (2007) Air Quality in Hong Kong 2007

Giridharan R, Ganesan S, Lau SSY (2004) Daytime urban heat island effect in high-rise and high-density residential developments in Hong Kong. Energy Build 36:525-534. doi:10.1016/j.enbuild. 2003.12.016
Guangdong Meteorological Bureau (www.grmc.gov.cn)(2007) Guangdong Climate Change Assessment Report (in Chinese)

Hong Kong Observatory Climate Change(2008) at http://www.hko.gov. $\mathrm{hk} /$ climate_change/ climate_change_hk_e.htm\# temperature

Lam CY (2006) On climate changes brought about by urban living. Hong Kong Meteorological Bulletin, 16(1/2), originally presented at PGBC Symposium 2006, 2 December 2006, Hong Kong, China (Hong Kong Observatory Reprint 700)

Lee YC, Savtchenko A (2006) Relationship between air pollution in Hong Kong and in the Pearl River Delta Region of South China in 2003 and 2004: an analysis. J Appl Meteorol Climatol 45 (2):269-282. doi:10.1175/JAM2332.1

Lee YC, Calori G, Hills P, Carmichael GR (2002) Ozone episodes in urban Hong Kong. 1994-1999. Atmos Environ 36(12):19571968. doi:10.1016/S1352-2310(02)00150-4

Leung, YK, Yeung, KH, Ginn, EWL and Leung, WM (2004) Climate change in Hong Kong. Hong Kong Observatory Technical Note No. 107.

Leung YK, Wu MC, Yeung KK (2007) Recent decline in typhoon activity in the South China Sea. International Conference on Climate Change, Hong Kong, China, 29-31 May 2007 (Hong Kong Observatory Reprint 708)

Liepert BG (2002) Observed reductions of surface solar radiation at sites in the United States and worldwide from 1961 to 1990. Geophys Res Lett 29(10):1421. doi:10.1029/2002GL014910

Lin CH, Wu YL, Lai CH, Lin PH, Lai HC, Lin PL (2004) Experiment investigation of ozone accumulation overnight during a wintertime ozone in south Taiwan. Atmos Environ 38(26):4267-4278. doi:10.1016/j.atmosenv.2004.05.003

Lin C-Y, Wang Z, Chou CC-K, Chang C-C, Liu SC (2007) A numerical study of an autumn high ozone episode over southwestern Taiwan. Atmos Environ 41(17):3684-3701. doi:10.1016/j.atmosenv.2006.12.050

NASA Aug.19,2008.NASA Study Improves Ability To Predict Aerosols' Effect On Cloud Cover. ScienceDaily (http://www. sciencedaily.com/releases/2008/08/080814163554.htm)

National Development and Reform Commission (2007) People's Republic of China. China's National Climate Change Programme.

NOAA Geophysical Fluid Dynamics Laboratory (2003) FY2002 Milestones: Determine the Impacts of Asian Emissions on North America

Olszyna KJ, Luria M, Meagher JF (1997) The correlation of temperature and rural ozone levels in southeastern USA. Atmos Environ 31 (18):3011-3022. doi:10.1016/S1352-2310(97)00097-6

People's Daily Online (2008-01-16) "South China Province Reports Worsening Air Quality”(http://english.peopledaily.com.cn/90001/ 90782/90872/6339255.html)

Roderick ML (2005) The ever-flickering light. Trends Ecol Evol 21 (1):3-5. doi:10.1016/j.tree.2005.11.005

Simmonds PG, Derwent RG, Manning AL, Spain G (2004) Significant growth in surface ozone at Mace Head, Ireland, 1987-2003. Atmos Environ 38(28):4769-4778. doi:10.1016/j. atmosenv.2004.04.036

Stanhill G, Cohen S (2001) Global dimming: a review of the evidence for a widespread and significant reduction in global radiation with discussion of its probable causes and possible agricultural consequences. Agric For Meteorol 107:255-278. doi:10.1016/ S0168-1923(00)00241-0

Tu J, Xia Z-G, Wang H, Li W (2007) Temporal variations in surface ozone and its precursors and meteorological effects at an urban site in China. Atmos Res 85(3-4):310-337. doi:10.1016/j. atmosres.2007.02.003

Vingarzan R (2004) A review of surface ozone background levels and trends. Atmos Environ 38(21):3431-3442. doi:10.1016/j. atmosenv.2004.03.030 